\title{
Análise de discurso francesa e teoria das representações sociais: algumas interfaces teórico-metodológicas
}

\author{
The french school discourse analysis and the theory of social representations: some \\ theoretical-methodological interfaces
}

\author{
Antonio Marcos Tosoli Gomes ${ }^{1}$
}

\begin{abstract}
RESUMO: O objetivo deste artigo consiste em analisar algumas das interfaces teóricas e metodológicas da análise de discurso da escola francesa com a teoria de representações sociais. Para isto, foram utilizados os principais elementos estruturais da análise de discurso, como as condições de produção do discurso, os dispositivos analíticos da análise de discurso e as formações discursivas e ideológica como unidades para a compreensão das possibilidades da concretização desta interface. A análise efetuada aponta que as representações sociais possuem papel integrador e de mediação entre a ideologia e as formações ideológicas, que a metáfora mostra-se como promissora para o levantamento do Núcleo Figurativo e da Dimensão Imagética das Representações Sociais e do Interdiscurso no que tange à Dimensão da Arqueologia da Representação e da Memória Social. Ao mesmo tempo, a paráfrase é identificada com o processo de continuidade de uma representação e a polissemia com a identificação de um subgrupo específico ou de um fenômeno de transformação representacional. Conclui-se que o discurso deve ser compreendido como uma totalidade significante e que o diálogo entre estes dois campos teóricos mostra-se promissor para ambos.
\end{abstract}

Palavras-chave: análise de discurso; representações sociais, pesquisa qualitativa.

ABSTRACT: The purpose of this article is to analyze some of the theoretical and methodological interfaces of the French school discourse analysis with the theory of social representation. For that, the main structural elements of discourse analysis were used, such as the conditions of discourse production, the analytical devices of discourse analysis, and the discursive and ideological formations as units to understand the possibilities of this interface implementation. The analysis points out that the social representations have an integrating and mediating role between the ideology and the ideological formations; and it also indicates that the metaphor shows to be promising for the survey of the Figurative Core and of the Imagery Dimension of the Social Representations as well as the Interdiscourse regarding the Dimension of the Archaeology of Representation, and of the Social Memory. Simultaneously, the paraphrase is identified with the continuity process of a representation, and the polysemy corresponds to the recognition of a specific subgroup or of a representational transformation phenomenon. Thus, the discourse should be understood as a significant totality; and the dialogue between these two theoretical fields proves to be promising for both.

Keywords: discourse analisys; social representations; research qualitative.

\section{Considerações iniciais}

De acordo com Cassirer (2012), o homem se consubstanciou como um animal symbolicum como fruto do seu processo evolutivo, diferenciando-o dos demais seres vivos. Este mesmo autor pontua que o pensamento e o comportamento simbólicos localizam-se entre as características mais importantes que ele possui - inclusive como fundamental para a sua caracterização como humano - e que o progresso e o desenvolvimento culturais são

\footnotetext{
${ }^{1}$ Pós-Doutor em Enfermagem; Professor titular da Faculdade de Enfermagem da Universidade do Estado do Rio de Janeiro - Rio de Janeiro, RJ, Brasil. E-mail: mtosoli@gmail.com.
} 
oriundos desta característica evolutiva. Mesmo que em seus respectivos cotidianos, homens e mulheres sejam marcados pela objetividade e pela razão analítica, simultaneamente estão atravessados por construções simbólicas e culturais que os permitem construir e manter sua identidade social e sua inserção em distintos grupos de pertença.

Esta marca de entrecruzamento vivido pelos seres humanos em seu processo de viver cotidiano, aquela que engloba os momentos repetitivos e cinzentos das obrigações diárias e que, simultaneamente, também abarca as situações singulares e não repetíveis de sua existência humana, é a do seu contexto objetivo e concreto, sujeito às organizações sociais, estrutura jurídica e aos posicionamentos alheios, que é reconstruído por sua subjetividade e por sua intersubjetividade, diminuindo as distâncias entre o exterior e o interior a ponto de se mesclarem em sua constituição como sujeito. Dentre as várias dimensões humanas que se apresentam como pontos nodais desta característica, deseja-se aqui destacar a linguagem, especialmente o discurso.

A linguagem de um modo geral e o discurso em particular se configuram como fenômenos que se localizam neste entremeio entre a objetividade exigida para a comunicação e o sentido produzido neste mesmo processo, ambos frutos de outra tensão que é a marca do social e do individual na produção discursiva (Orlandi, 1986, 2001a, 2001b). É indubitável que a singularidade das características psicológicas de um indivíduo está impressa no discurso produzido e na comunicação efetuada, proveniente de uma história pessoal e dos mecanismos mentais, cognitivos e particulares ativados frente às temáticas englobadas por dois ou mais sujeitos que mantém um diálogo (Orlandi, 2002, 2003). Isto pode ser observado ainda no fato de que a maior profundidade de relacionamento entre duas pessoas, propicia maior entendimento das palavras usadas e do sentido que se quer impregnar a construção verbal ou a expressão não-verbal.

Se a marca da singularidade se mostra como indubitável, o social também está presente na produção do discurso de maneira inequívoca. Se não fosse assim, a comunicação entre diferentes grupos se caracterizaria como um desafio quase intransponível e os equívocos de sentido produzidos pela linguagem inviabilizaria a compreensão mútua. Neste sentido, o discurso é marcado pela história e pelo social como construção de um determinado grupamento humano em um local específico. A história enriquece a linguagem reportando-a a tempos imemoriais, inclusive de encontros que foram esquecidos e que, por isto, geram troncos comuns em contextos de diferentes línguas, ao mesmo tempo em que a conforma com as singularidades de um grupo social específico.

$\mathrm{Na}$ medida em que se considera que o ser humano é, por essência, um animal simbólico e que as construções simbólicas são importantes no processo de produção discursiva, vide os constantes equívocos a que estamos submetidos, é que o objetivo deste artigo se configura como analisar algumas das interfaces teóricas e metodológicas da análise de discurso da escola francesa (Pêcheux, 1996, 2001) com a teoria de representações sociais (Moscovici, 1961, 2003, 2012). Para isto, optou-se por apresentar os elementos estruturais da análise de discurso aprofundando as suas interfaces com as representações sociais, uma vez que estes tendem a ser os mais distantes e estranhos para a maioria dos leitores do presente periódico. Inclusive, por ser uma análise do diálogo entre os dois campos, considera-se desnecessária a definição dos principais conceitos presentes na teoria de representações sociais ou da análise de discurso por se partir do pressuposto de que estes estão devidamente compreendidos. 


\section{As estruturas de interface entre a análise de discurso e as representações sociais}

Como ponto de partida para a análise proposta, deve-se reconhecer que diversos pontos de interfaces poderiam ser destacados entre ambos os campos teóricos. Em função disto, foram priorizados, neste momento, aqueles pontos que podem ser considerados estruturais para a análise de discurso, como as condições de produção do discurso, os dispositivos analíticos da análise de discurso e as formações discursivas e ideológica. Destacam-se, portanto, as limitações que esta opção acarreta para a análise efetuada, mas, simultaneamente, acredita-se na restrição destas limitações à medida que se optou por abarcar os principais elementos organizadores dos processos discursivos utilizados pela análise de discurso.

\section{Condições de produção do discurso}

O dito para Pêcheux (1996, 2001) e Orlandi (2001a) é definido como tudo que foi explícito pelos sujeitos em seu processo de comunicação e de diálogo, quer seja verbalmente ou por outras vias de socializa-lo. O não-dizer, por sua vez, possui seu sentido na relação com o dizer (e vice-versa), mas não se mostra explicitamente. Para Pêcheux (2001), o não-dito só pode ser alcançado através do que ele chama de "exterior específico", e que posteriormente denomina de Condições de Produção do Discurso. Para este autor, o não-dito é a definição de uma "ausência específica daquilo que está presente em outro lugar" (p. 149). Orlandi (2001a, 2002), ao mesmo tempo, aprofunda a especificidade de algumas modalidades do não-dizer, como aquele que deriva da própria instância da linguagem - o denominado pressuposto - e aquele que se dá em um contexto (o subentendido). Conclui, ainda, que várias noções da análise do discurso encampam o não dizer. Dentre elas, ressaltam-se o interdiscurso, a ideologia, a formação discursiva e as formas do silêncio.

As condições de produção do discurso é um conceito fundamental à análise de discurso francesa e um importante ponto onde se pode observar a presença dos elementos sociais, grupais, contextuais, políticos e culturais que influenciam no dito e que, ao mesmo tempo, conformam o não-dito. Este conjunto de fenômenos, contextos, situações e, especialmente, ideologias formam uma rede de representações que alimentam uma determinada forma de pensamento social em que o dito se constrói de uma determinada maneira e outras possibilidades do dito são impedidas por sua não coerência com o conjunto das representações construídas.

Por isto, destaca-se que, se por um lado, o discurso é um substrato fundamental às pesquisas em representações sociais, por outro lado, os pesquisadores que o possuem como elemento principal de análise, devem ter em mente esta capacidade plástica que ele possui como forma de se adaptar à construções imaginárias que se constroem no próprio ato de produzir sentido no diálogo. Um discurso produzido em uma entrevista de emprego com o futuro chefe é construído a partir de um conjunto de representações do que é um bom empregado, da eficácia das ações diárias e do perfil humano e profissional necessário para a ocupação da vaga, em consonância, de um modo geral, com o máximo de margem de liberdade pós-admissão que se consiga negociar neste momento.

Ao mesmo tempo, o discurso de um líder religioso é elaborado de maneira a atender a ortodoxia do corpo doutrinal de sua religião, mesmo que possua reflexões que permitam 
compreensões mais flexíveis em determinados pontos. O difundido discurso do Papa Francisco retornando do Brasil para Roma acerca de sua ação de acolhimento no seio da Igreja Católica dos homossexuais que se aproximam da fé e do transcendente sem maiores exigências, produziu o sentido de diminuição do abismo que existia entre os grupos religiosos e os homossexuais, sem, no entanto, descambar para uma heterodoxia, em que uma ruptura brusca poderia desconstruir as representações do que é um papa para uma boa parte de católicos. Ou seja, percebe-se que o discurso é organizado a partir de um conjunto de representações que configuram determinados pensamentos sociais que são ativados sociocognitivamente, dependendo do local em que se está e do papel social que cada pessoa compreende ter, assim como das representações que outros grupos sociais possuem da pessoa em tela (o professor, acerca de seus alunos; o papa, dos católicos; os políticos, de seus eleitores; e assim sucessivamente).

Isto significa dizer que o discurso possui uma exterioridade que deve ser compreendida como forma de melhor delimitação do sentido produzido, ou seja, de que existe uma coerência interna ao discurso efetuado - aprofundado mais à frente - que só pode ser compreendida levando-se em consideração a ou as representações que influenciam nesta mesma produção. Assim, para se trabalhar com a análise de discurso e a teoria de representações sociais, na delimitação do objeto de estudo, deve-se ter em mente os diferentes objetos representacionais que podem estar presentes em sua construção, o contexto imediato que se configurou como cenário da coleta de dados e os acontecimentos políticos e culturais que cercam este mesmo momento da coleta.

O estudo da aids, por exemplo, mostra-se marcado pelas representações da pessoa que vive com a síndrome e do conhecido "coquetel", por elementos de religiosidade que fazem a ancoragem da aids em determinadas representações sociais arcaicas (no sentido arqueológicas) e pela evolução política e sanitária da atenção à síndrome no Brasil, dentre outros aspectos que poderiam ser citado (Jodelet, 1998). Ao mesmo tempo, o dado empírico produzido acerca deste objeto, terá as marcas de contexto mais imediato no que tange à sua coleta: quem o coletou e onde o fez podem influenciar na produção discursiva dos sujeitos. A resposta a uma pessoa envolvida com a gestão em nível central do programa em DST/Aids tende a exigir respostas mais elaboradas e contextualizadas, ao passo que esta mesma resposta dada a outra pessoa em que não exija, simbolicamente, tamanha pressão normativa, pode diferir em conteúdo, em forma de passá-lo ou em ambos.

Com esta divisão em um contexto mais amplo e estrito da produção discursiva alimentada por conjuntos e redes de representações é o que pode ser denominado de Condições de Produção do Discurso. Este conceito substituiu o que Charaudeau (2008, p. 114) chamou de "noções muito vagas de 'circunstâncias' nas quais um discurso é produzido", explicitando que o objetivo é delimitar, de uma maneira mais objetiva, os aspectos, de um lado mais gerais e, do outro, mais específicos, que condicionam o discurso. Este conceito surge em Pêcheux (2001) e é depois retomado por outros autores da análise de discurso na esteira do pensamento de que um estado determinado das condições de produção do discurso corresponde, necessariamente, a variantes semântico-retóricas que se mantém estáveis no contexto dos mesmos quadros.

$\mathrm{Na}$ interface entre a análise de discurso com a teoria das representações sociais e aprofundando as questões expostas nos parágrafos anteriores, concorda-se com Charaudeau (2008) de que Pêcheux realiza um corte epistemológico na teoria de 
comunicação, onde se supera a ideia de polos como destinador e destinatários e de uma emissão de informação impermeável a outros fatores, exceto o código e a mensagem, por um encontro mediado pelo processo simbólico, que vai da ideologia que marca o discurso a construções imaginárias que medeiam as relações entre sujeitos. É neste espaço que se considera que as representações possam ser reconstruídas em um complexo encontro entre auto e heterorepresentações que formam uma determinada posição social que permite o dizer algo de uma maneira específica e impede o dito de outras formas ou de outros objetos.

Neste processo, Pêcheux (2001, p. 82) considera que "existem nos mecanismos de qualquer formação social regras de projeção, que estabelecem as relações entre as situações (objetivamente definíveis) e as posições (representações dessas situações) ". Destaca-se que se deve evitar o estabelecimento de qualquer relação mecânica entre situações e posições e que a configuração de ambas e a mútua influência deve ser alvo de atenção nos estudos empíricos desenvolvidos que desejem trabalhar com estes dois conjuntos teóricos (análise de discurso e representações sociais). Esta complexa relação entre situação e posição não somente modula o dito e o não dito, mas o faz a partir de um processo de antecipação discursiva, em que, como afirma Pêcheux (1996), todo processo discursivo supõe uma antecipação das representações do receptor (heterrepresentações), que se entrelaça com as representações de si e de sua posição (autorrepresentações).

\section{Dispositivos analíticos da análise de discurso e a teoria de representações sociais}

Quando se pensa em dispositivos analíticos, deseja-se abarcar um conjunto de processos discursivos que se tornam marcações importantes para a realização da análise de discurso. Estes dispositivos se configuram como importantes centros de produção de sentido de onde se pode perceber a presença das representações sociais como marca do pensamento social que conforma este mesmo processo. Dentre os discursos analíticos, aprofundaremos a paráfrase, a polissemia, o interdiscurso e a metáfora.

Pêcheux (2001, p. 169) refere que "a produção do sentido é estritamente indissociável da relação de paráfrase" e que a família parafrástica de um determinado corpus "constitui o que poderia chamar de matriz de sentido", ao passo que, para Orlandi (2001a), os processos parafrásticos são aqueles pelos quais em todo dizer há sempre algo que se mantém, isto é, o dizível, a memória. A paráfrase representa, assim, o retorno aos mesmos espaços do dizer, apresentando diferentes formulações do mesmo dizer que já se encontra sedimentado, o que significa que este dispositivo pode ser identificado na tendência à estabilização da elaboração do processo discursivo.

A paráfrase encontra-se na genealogia de verdadeiras famílias de dizer em que a repetição e o retorno ao dizível encontra-se disponível como matriz de sentido que permite que o diálogo se estabeleça e que o dizer mostre a sua dimensão histórica e social. Formase, de fato, o que Pêcheux (2001, p. 170) denomina de "arqueologia regular" do processo discursivo e isto torna a paráfrase fundamental para uma análise empírica de dados. Esta arqueologia não é aprofundada por Pêcheux em sua obra seminal e é um conceito que ainda carece de maior aprofundamento teórico e evidência empírica, mas se constitui como uma proposta fundamental ao diálogo entre a teoria de representações sociais e a análise de discurso. Nesta arqueologia, considera-se que existam um conjunto de memórias sociais e de representações que, como veremos à frente, são alimentadas por ideologia (s) e mantém 
uma estabilidade de estrutura, de conteúdo e de apresentação do discurso, mesmo que se mantenha invisível e seja sutil em seu trabalho.

Este dispositivo apresenta-se como indispensável na realização da análise de discurso, pois todo o dizer vai se estruturando a partir de famílias parafrásticas, que dão continuidade espaço-temporal ao sentido constituído em algum ponto da linha histórica do grupo social ou da sociedade. Por isso, este elemento possui a capacidade (em maior ou menor grau, dependendo da particularidade do discurso realizado) de aglomerar os demais dispositivos analíticos, uma vez que, com a sua ausência, não existiria um continuum no discurso, mas somente transformações sucessivas e ininterruptas que caracterizariam o processo de formulação das enunciações (Orlandi, 2001a; Pêcheux, 2001).

Apesar dos discursos serem construídos parafraseando o vivido (ouvido, lido, aprendido, intuído e percebido, dentre outras ações), em alguns momentos consegue-se realizar uma ruptura e experimentar um sentido novo no dito cotidiano. E é nesse jogo que os sujeitos e os sentidos se movimentam, fazem seus percursos e significam ao mundo e a si mesmos. Orlandi (2001a, p. 37) ainda acrescenta que "se o real da língua não fosse sujeito à falha e o real da história não fosse passível de ruptura, não haveria transformação, não haveria movimento possível, nem dos sujeitos, nem dos sentidos". É justamente pelo fato da língua ser sujeita ao equívoco e a ideologia se caracterizar por ser um ritual que influencia que o sujeito, que este, ao significar, se significa. Por isso, destaca-se, como condição sine qua non, que a incompletude é a condição da linguagem: nem os sujeitos, nem os sentidos, logo, nem o discurso, já estão prontos e acabados e, por isto, estão sempre expostos à acidentalidade humana do encontro e do desencontro, como bem expõe Arendt (2010).

Por isso, deve-se sempre considerar que os sentidos poderiam ser outros, como consequência da ruptura de sentido sempre possível, mas, de um modo geral, nunca esperado. Contudo, o fato de nem sempre essa ruptura ocorrer, relaciona-se ao modo como os sujeitos enunciadores são afetados pela língua, se inscrevem na história e afetam e são afetados pelo jogo entre paráfrase e polissemia. Dessa maneira, Pêcheux $(1996,2001)$ e Orlandi (2001a) consideram que o funcionamento da linguagem e a produção de sentido se fundamentam na tensão entre os processos parafrásticos e os polissêmicos. A polissemia, contrapondo-se à paráfrase, é definida como o deslocamento, a ruptura na continuidade perpetrada pela paráfrase, a solução de continuidade no processo de significação (que é mantida pela paráfrase), jogando permanentemente com o equívoco (Orlandi, 2001a). Essas são as duas forças que atuam de forma contínua no nosso dizer, com tal intensidade que o discurso se constrói a partir dessa tensão: entre o mesmo (paráfrase) e o diferente (polissemia).

Segundo Amaral e Rodrigues (2012), baseando-se em Orlandi (2001), a paráfrase representa "o mesmo", enquanto a polissemia "o diferente", e nesta tensão, garante-se a permanência contínua da historicidade na medida em que a paráfrase assegura o já-dito oriundo da história passada no presente, ao mesmo tempo em que a polissemia instaura a ruptura que possibilita outro sentido, trazendo para este jogo a noção de futuro. Nesse sentido, o trabalho da polissemia garante continuidade de existência discursiva, de existência de sujeito no decorrer da história, garante a possibilidade da produção de outros discursos. De um lado, a paráfrase prende uma ponta do discurso ao passado, à historicidade transportada pela ideologia; de outro, a polissemia lança outra ponta do discurso na direção do novo, do que é criativo. 
À medida que a paráfrase se apresenta como matriz de sentido, especialmente em sua tensão com a polissemia, a ele também se liga outro processo discursivo que se constitui como a memória do dizer, o interdiscurso. Em função disso, deve-se considerar que a memória, por sua vez, tem suas características, quando pensada em relação ao discurso. 0 interdiscurso é definido como aquilo que fala antes, em outro lugar, independentemente. Ou seja, é o que chamamos memória discursiva: o saber discursivo que torna possível todo dizer e que retorna sob a forma do preconstruído, o já-dito que está na base do dizível e que sustenta cada tomada da palavra. $O$ interdiscurso disponibiliza dizeres que afetam o modo como o sujeito significa em uma situação discursiva dada (Orlandi, 1996).

O interdiscurso possui a propriedade, segundo Maingueneau (2008), de deixar perceber, para o analista de discurso, a relação multiforme que estabelece com os demais discursos já veiculados e, geralmente, esquecidos, sem origem determinada. Manifesta-se através do entrecruzamento de diversos discursos que mantém relações de delimitação recíproca de uns com os outros ou, como afirma Courtine (1981), é uma articulação contraditória de formações discursivas que se referem a formações ideológicas antagônicas. Este dispositivo mostra as diferentes ideologias presentes na visão de mundo de um determinado grupo social acerca de um objeto específico e que são reproduzidas na produção discursiva.

O interdiscurso se organiza ao redor de objetos representacionais já consolidados em determinados grupos, o que faz com que, neste derredor, se aglutinem construções simbólicas que são adquiridas como sendo próprias dos sujeitos. Quando se inclui, em uma discursividade, a expressão "beijo de Judas", ativa-se a representação de uma traição realizada através de um ato camuflado de amizade e delicadeza, situação esta presente no processo de construção simbólica do ocidente cristão como um interdiscurso que substitui, de maneira compacta, uma longa explicação e detalhamento de uma situação real de traição por um amigo ou pessoa próxima. Esta mesma expressão pode ser raramente usada e nem sempre ter sentido em um território budista ou islâmico.

Este fato se deve porque o interdiscurso se alimenta necessariamente de uma visão orgânica e coerente do mundo social em que se está inserido, que, por sua vez, é alicerçada em representações sociais que permitem que os sujeitos se locomovam no mundo e em seus grupos sociais. Por isto, Charaudeau (2009) considera que o interdiscurso se estrutura como um jogo de reenvios e de interação que tem, por base, um suporte textual, mas cuja origem e configuração não se tem memória e nem delimitação histórica. Quando uma determinada empresa de chocolate veicula um comercial de bombom com papel dourado e caindo do Olimpo para a terra, necessita de elementos de interdiscursividade como a elevação moral e ética das divindades, a simbologia da cor dourada, o sublime e inigualável apetite dos deuses e as mitologias, em que algo divino chega ao mundo dos homens e o altera para todo o sempre.

Nos estudos de representações sociais, deve-se considerar que o interdiscurso, no processo de análise de dados empíricos, deixa apreender a ideologia que organiza e sustenta estas mesmas representações, ao mesmo tempo em que pode fornecer "pistas" para se compreender a ancoragem de um determinado objeto. Neste sentido, deve-se destacar que este dispositivo analítico pode ser um instrumental interessante para a explicitação dos elementos simbólicos e discursivos que estão na gênese das representações estudadas. 
O interdiscurso, neste sentido e como já pontuado, "sustenta o dizer em uma estratificação de formulações já feitas, mas esquecidas, e que vão construindo uma história de sentidos" (Orlandi, 2001a, p. 54), caracterizando-o como a memória discursiva. É através dessa memória que nossos sentidos se constroem, dando-nos a impressão de sabermos do que estamos falando e de que o nosso dizer possui origem exclusiva em nosso pensar. $\mathrm{O}$ que particulariza o interdiscurso é o esquecimento e a posterior disponibilização desses já ditos esquecidos que não possuem origem definida, mas se mantém presente nas relações estabelecidas no âmbito social. Outro aspecto importante da relação entre o interdiscurso e a teoria de representações sociais, é a possibilidade de aprofundamento da memória social de determinados grupos sociais, por sua capacidade de retirar dos "escombros" maneiras próprias de dizer que estão disponíveis na convivência social, mas cujas origens se perderam no tempo.

Outro conceito importante à análise de discurso é a de metáfora e, para Pêcheux (1996), Pêcheux e Fuchs (2001) e Orlandi (2001a), o efeito metafórico é constitutivo do processo de produção de sentido. Bonhome (2008), de um modo geral, considera este dispositivo a figura mais importante do processo discursivo, destacando que ela designou diversas transferências de denominação na filosofia antiga e que, atualmente, em geral, comporta a ideia de transferência por analogia. A metáfora possui três funções básicas no que tange à produção discursiva: a estética, a cognitiva e a persuasiva.

A estética da metáfora deve-se à ideia de força imagética (Henry, 1971) e dos efeitos de concretização que decorrem desta força, oferecendo um corpo concreto, de maneira relativamente rápida, a uma impressão difícil de exprimir (Bachelard, 2000), com a presença frequente de paráfrases e tentativas de uso de polissemias. A cognitiva, segundo Bonhome (2008, p. 330) apresenta um "forte rendimento heurístico", na medida em que permite explicar analogicamente um domínio novo ou pouco definido por um conhecido e que faça parte das construções simbólicas e representacionais de um grupo em particular. Permite, assim, um processo de "familiarização" do novo a partir de construções anteriores. A persuasiva, por sua vez, relaciona-se à característica de impor opiniões sem a necessidade de demonstrá-la (a palavra "bíblia" é intercambiável no discurso cotidiano e teológico com a expressão "palavra de Deus"). Esta força persuasiva refere-se a uma analogia condensada e a um julgamento de valor concentrado que se estabelece em um acordo preliminar socialmente aceito (Bonhome, 2008).

Para Pêcheux (2001), o efeito metafórico é um fenômeno semântico caracterizado por ser uma substituição contextual a partir de um deslizamento de sentido entre duas ou mais palavras, definindo, assim, o sentido de todas elas na organização e coerência internas de um determinado discurso. A metáfora desmonta a ideia de existência de uma metalíngua onde os sentidos de cada palavra já estariam, de per si, definidos externamente e impermeáveis aos equívocos cotidianos característicos da discursividade. Portanto, torna-se necessária um corpus com tamanho considerável para que se consiga colocar em evidência os pontos de ancoragem semântica que são as metáforas. Ou seja, para Pêcheux (2001, p. 97), a metáfora coloca em evidência o que entendemos por conservação da invariante através da variação morfemática, onde "o mesmo sistema de representações se inscreve através de variantes que o repetem progressivamente".

A constância do idêntico, repetido e mantido por vias e signos distintos, caracteriza uma complexa produção de sentido no processo discursivo. Quando se estuda grupos sociais 
a partir da teoria de representações sociais e observa-se esta singularidade do processo simbólico em substratos linguísticos diferentes, considera-se que se está defronte de um processo representacional compartilhado pelo grupo, atravessando sua intersubjetividade e despontando em seu discurso.

\section{Formação discursiva e formação ideológica}

A noção de formação discursiva foi elaborada por Foucault e depois reapropriada por Pêcheux (2001), onde ganha, de fato, uma aplicabilidade mais delimitada na análise de discurso. Em um primeiro momento, este autor considerava que toda formação social, caracterizada por relações entre classes sociais implicava na existência de posições políticas e ideológicas que não são individuais, mas se organizam em formações que mantém diferentes relações entre si, como antagonismo, aliança e dominação. As formações ideológicas carreiam e organizam, ao redor de si, as formações discursivas que possuem relação com esta construção ideológica, determinando o que pode e o que deve ser dito, a partir de uma posição e uma conjuntura específicas. Esta complexa relação entre a formação ideológica e as formações discursivas apresenta influência sobre a semântica, uma vez que uma palavra só possui sentido no contexto de uma determinada formação discursiva, ao mesmo tempo em são estas formações que operam o assujeitamento e a interpelação do sujeito como sujeito ideológico (Maingueneau, 2008; Orlandi, 2001a; Pecheux, 2001).

No final da década de 70 do século passado, o próprio Pêcheux revisita o conceito de formação discursiva no sentido de atenuar a sua forte identidade e estabelecer, de maneira mais fluida, sua relação com o interdiscurso, configurando-se como um fenômeno inseparável deste. No dizer do próprio autor (Pêcheux, 2001, p. 314), "uma formação discursiva não é um espaço estrutural fechado, pois é constitutivamente 'invadida' por elementos que vem de outro lugar (isto é, de outras formações discursivas) que se repetem nela, fornecendo-lhe suas evidências discursivas fundamentais (por exemplo, sob forma de 'préconstruídos' e de 'discursos transversos') ". Segundo ainda o próprio Pêcheux (1996), a noção de interdiscurso introduz a ideia do exterior específico de uma formação discursiva, ao mesmo tempo em que a constitui como uma instância na estrutura do sentido destinada à repetição estrutural fechada. Neste sentido, mantém-se a ideia de uma estrutura na análise de discurso pecheutiana, mas de uma maneira mais fluida, comportando um processo de atualização mais constante do que se fosse algo mais fixo.

Orlandi (2001a, 2001b) considera que ainda que a definição de formação discursiva seja polêmica e sem consenso na análise de discurso, ainda é básica e fundamental para esta área do conhecimento, pois permite, ao analista, três processos: (1) apreender o processo de produção de sentido por um grupo determinado; (2) explicitar a sua relação com a ideologia que a fomenta e que dá sentido ao dito; e (3) estabelecer regularidades ao discurso.

Um dos pontos fundamentais da análise de discurso é a abordagem da ideologia como um elemento central para a compreensão do sentido produzido. Orlandi (2001a) considera que se a apreensão do sentido presente no processo discursivo localiza-se na interpretação e que a interpretação, por si mesma, confirma a presença e a ação da ideologia. A questão fulcral é que o movimento que leva o sujeito a interpretar, como se a interpretação sempre estivesse disponível da forma natural como se apresenta, tende a se 
configurar como uma evidência do trabalho da formação ideológica. Há, portanto, um processo de naturalização dos fenômenos e dos fatos em que em que se depreende que a única interpretação possível é a que se tem, por um mecanismo de apagamento do próprio mecanismo de interpretação, como se a linguagem e a história não portassem espessura e como se não se caracterizasse por opacidade (Orlandi, 2001a).

Orlandi (2001a), baseada em Pêcheux (2001), considera que a característica comum da ideologia é a de se tornar transparente no seu próprio processo de funcionamento, produzindo um tecido de evidências subjetivas, isto é, evidências nas quais o indivíduo se torna sujeito. Assim, a ideologia não é ocultação, mas função da relação necessária entre linguagem e mundo, ou seja, "linguagem e mundo se refletem no sentido da refração, do efeito imaginário de um sobre o outro" (p. 47). A relação se estabelece na linha sequencial de que não há discurso sem sujeito e, simultaneamente, não há sujeito sem ideologia, uma vez que é a interpretação que que realiza a relação do sujeito com a língua, com a história e com o sentido.

\section{Algumas considerações acerca da interface da análise de discurso com a teoria de representações sociais}

A análise de discurso e a teoria de representações sociais possuem alguns entraves epistemológicos e algumas áreas de interface que se configuram como promissoras, caso sejam aprofundadas. O principal entrave que se pode destacar é uma abordagem mais individualizante da análise de discurso em função de uma de suas bases ser a psicanálise e o seu desdobramento em conceitos fundantes da análise de discurso, como o de formação discursiva, por exemplo, como bem apontam Orlandi (2001a). Por outro lado, como área promissora, o conceito de ideologia, realizando sua crítica acerca de aspectos psicanalíticos abordados por Pêcheux (2001) na utilização deste conceito, torna-se um importante ponto de aproximação, especialmente por sua capacidade de análise macrossocial dos objetos representacionais.

Considera-se que uma ideologia apresenta-se como uma cosmovisão estabelecida (Guareschi, 2000) que estimula a construção simbólica de diferentes objetos representacionais, construindo uma complexa estrutura sóciocognitiva e simbólica. O fato de não serem muitos os trabalhos que abordaram a questão da ideologia nos estudos de representações sociais (como exceção, destacam-se, especialmente, as obras de Deconchy (1989) e Rouquette $(1996,2009)$, que se debruçaram teoricamente para compreender esta relação, mas também de Jodelet (2001), Guareschi (2000) e Santos (1994) que o fizeram de maneira mais pontual), tende a deixar frágil a apreensão das relações destas representações com a sua exterioridade, apontando seu contexto maior e a historicidade dos objetos abordados. A mesma coisa se dá na necessidade de associar o estudo da ideologia em conjunto com o do processo de formação das representações, quais sejam, a ancoragem e a objetivação, uma vez que estes processos possuem uma história e uma conformação que sofre influência de uma determinada organização social em um espaço e tempo delimitados (Jodelet, 2001; Xavier, 2002).

Sem este cuidado, a análise destes processos pode ficar restrita às fronteiras da própria teoria, como se a ancoragem e a objetivação fossem fim em si mesmas e não fruto de um complexo processo de constituição de esquemas simbólicos, que, ao mesmo tempo, 
alimentam e são alimentados por formações ideológicas dinâmicas e sensíveis às transformações sociais, especialmente na época atual, onde a intensa produção de conhecimento e sua rápida difusão em todo o planeta tornam os processos sociais mais rápidos e, em alguns casos, mais sutis. Do mesmo modo, a aproximação do conceito de ideologia com os processos de formação das representações sociais poderá contribuir para uma investigação mais acurada das negociações sociais e simbólicas que se estabelecem como trocas cotidianas não só para uma definição mais acurada da relação entre representações e práticas, mas também para um aprofundamento das diferentes navegações sociais que se estabelece quando se vence o oficial a partir das sutilezas do oficioso permanentemente negociado, no Brasil o tão conhecido "jeitinho" devidamente apresentado por DaMatta (1986).

Deve-se destacar que poucos estudos aprofundam, de fato, a relação estabelecida entre as representações sociais e a ideologia, com destaque especial para a obra de Santos (1994), que o fez desde a década de 90, seguida de autores como Guareschi (2000), Franco (2004) e Xavier (2002). Rateau, Ernest-Vintila e Delouvée (2012), ao se debruçarem sobre a produção de Michel-Louis Rouquette e a sua interface com o modelo de arquitetura do pensamento social, destacam que esta arquitetura possui polos mais instáveis ou particulares que se contrapõem a polos mais estáveis e gerais, sendo que, dos primeiros aos últimos, tem-se as seguintes etapas: opinião (ões), atitude (s), representação (ões) social (is) e ideologia. Em um primeiro momento, destaca-se a singularidade de uma ideologia que se localiza no ápice da estrutura do pensamento social, à qual se ligam uma ou mais representações sociais e posteriormente atitudes e opiniões. A utilização deste tipo de estrutura ou de algo que compreenda as representações sociais dentro de uma coerência maior do pensamento social ou de uma arqueologia de construção simbólica tende a explicitar algumas relações que podem permanecer escondidas de outro modo.

Além disto, a teoria das representações sociais caracteriza-se por ser uma psicossociologia do conhecimento e tem, como substrato privilegiado, o processo de comunicação, que, por sua vez, possui sua unidade básica na palavra. Embora haja inúmeras divergências entre os campos e os autores da linguística, da teoria do discurso e da semiótica, um ponto relativamente consensual é o de que a palavra é um fenômeno ideológico por natureza, especialmente depois das contribuições teóricas de Bakhtin (1992a, 1992b). Desta maneira, adota-se a hipótese de que a consideração da relevância da dimensão ideológica das palavras nos estudos em representação possa aprofundar ainda mais as características dos processos sociocognitivos, onde contextos representacionais possam iluminar os sentidos presentes nos processos discursivos acerca de um determinado objeto. Consegue-se observar, por exemplo, que os estudos que aprofundam a compreensão representacional da aids, diversas palavras, como praga e peste, possuem forte ideologia religiosa e ganham sentido neste contexto, qual seja, o de castigo divino, alimentando-se de construções simbólicas arcaicas presentes na memória social da humanidade como um todo e em grupos religiosos em particular.

O conceito de formação discursiva mostra, ainda, outra dimensão desta interface com a teoria das representações sociais, uma vez que se pode compreendê-la como fruto de uma ou mais representações que a alimentam, a sedimentam em um determinado contexto espaço-temporal e, também, a fragilizam e a transformam em outros contextos, sempre em consonância (não mecanicamente determinada) com esta exterioridade. A relação entre representações e formações discursivas explicaria, inclusive, a regularidade do discurso ao 
longo do tempo e dos grupos, uma vez que uma mudança da estrutura da discursividade dependeria da transformação das formações discursivas e estas, por sua vez, das representações. Ao mesmo tempo, a relação estabelecida entre as representações sociais e as formações discursivas permite uma percepção mais dinâmica entre ambas, na medida em que inclui a presença de auto e heterorrepresentações na construção das margens do dizer e na tomada do que pode ser considerado como atitude discursiva, como afirma Charaudeau (2009).

Para este autor, as atitudes discursivas possuem íntima relação com a identidade discursiva e podem se desdobrar nos seguintes comportamentos em um processo discursivo: de neutralidade, de distanciamento, de engajamento, de sedução, de polemização e de dramatização. Além disto, destaca-se que um dos aspectos mais interessantes deste ponto é o casamento entre a identidade discursiva (por sua vez relacionada à identidade social) e a tomada de posição no ato de enunciação. Os estudos em representações sociais são promissores para uma melhor delimitação desses conceitos e por sua integração na análise de discurso francesa para se entender a estrutura de um determinado pensamento social - no caso, as representações -, o modo como este pensamento é verbalizado nas interações cotidianas, a forma como são adotadas as atitudes no processo de comunicação e as práticas sociais e discursivas desenvolvidas no conjunto das interações desses processos.

Deve-se, ainda, considerar como a teoria da identidade social (Tajfel, 1972; Monteiro, 2013) pode contribuir para uma melhor delimitação da formação discursiva, uma vez que grupos sociais se movimentam para dar conta de processos de interação, tanto objetivos, como simbólicos, o que determina uma forma de dizer e, mesmo que parcialmente, constitui-se em uma das origens dos sentidos das palavras. No entanto, na análise destes fenômenos e até mesmo de instâncias estruturais da relação entre as representações sociais e a análise de discurso, deve-se ter uma prudência acadêmica para que não haja uma simplificação destas relações e nem a apreensão limitada a causas e efeitos, tornando superficial a complexidade deste encontro teórico.

Para finalizar esta parte da discussão, concorda-se com Marková (2006) e Bakhtin (1997) quando afirmam que ser e comunicar-se são duas ações intercambiáveis e que, de maneira privilegiada, o ser se concretiza no diálogo com os demais (a alteridade), e que o exercício do dizer é, necessariamente, uma forma de pensar o mundo e, mesmo que de maneira incompleta, de também reconstruí-lo simbólica e sociocognitivamente. A análise de discurso, ao longo dos últimos anos, vem compreendendo que pode ter um papel importante na forma de compreensão da realidade e de aprofundamentos dos sujeitos e dos grupos sociais a ponto de um dos seus ramos ser classificada como crítica, trazendo para si responsabilidades de colaboração nas transformações sociais.

Com relação aos dispositivos analíticos, são apontadas, a seguir, algumas questões fundamentais de cada um deles no que tange à sua aplicação no contexto dos estudos em representações sociais, sem a pretensão de ser exaustivos e/ou conclusivos. São, na verdade, algumas interfaces que permitem o desenvolvimento de estudos empíricos com o uso destas duas abordagens.

Ressalta-se que a preocupação na apreensão e delimitação dos processos de paráfrase na discursividade engendrada descortina as suas dimensões e/ou os elementos mais permanentes e centrais da representação, ou seja, aqueles elementos que 
permanecem em uma determinada evolução temporal, mantendo a sua estabilidade e, assim, gerando famílias discursivas consecutivas que retornam, permanentemente, ao mesmo dizer e ao mesmo espaço do dizível. A centralidade destas dimensões e/ou elementos representacionais fornece uma coerência interna à produção discursiva e impede que haja sucessivas e constantes transformações na estrutura do dizer, especialmente em seu arcabouço interno, que é a matriz que o estabiliza. Neste sentido, o elemento de estabilidade discursiva relaciona-se ao conjunto estrutural do dizer e às interações que os elementos possuem entre si e não somente a presença ou ausência de determinadas palavras e/ou expressões.

A polissemia, por sua vez, quando presente de maneira pontual na discursividade estudada pode-se considerar a existência de subgrupos representacionais que mostram a presença de novos sentidos quando comparados com aqueles já percebidos no conjunto dos sujeitos. Na medida em que se considera que exista uma organização maior do discurso a partir dos processos polissêmicos, deve-se aprofundar a hipótese de mudança representacional em curso. Desta maneira, a permanência de uma construção representacional ou a sua mudança pode ser percebida, mesmo que de forma mais indicativa do que afirmativa, na relação que se estabelece entre a paráfrase e a polissemia, sendo que a definição destes dois conceitos deve se dar na coerência interna do texto produzido pelo discurso e não a partir de uma referência necessariamente externa que defina o que é a continuidade de sentido ou a sua ruptura.

Com relação à metáfora, considera-se que os diversos deslizamentos de sentidos que ocorrem entre diferentes palavras e expressões relacionam-se à(s) imagem(ns) que compõe $(m)$ o objeto representacional estudado. Neste caso, este dispositivo permitiria o levantamento de diferentes imagens (deslizamentos) para um único elemento representacional, configurando um caleidoscópio de imagem, que subsidiaria, em alguns casos, inferências empíricas acerca do núcleo imagético de uma representação. Quanto ao interdiscurso, este dispositivo ganha importância ao se trabalhar com objetos normativos em que se deseja apreender as diferentes construções simbólicas construídas ao longo do tempo em uma sociedade específica ou em determinados grupos sociais, permitindo que os dizeres com os quais estas pessoas tiveram contato e que foram absorvidos por seu sistema sociocognitivo possam reaparecer em seus discursos com a ilusão de que esta produção discursiva é de autoria do falante naquele momento específico. 0 interdiscurso possui relevância ainda para os estudos de memória social, tendo como material principal de análise a evolução da memória discursiva presente nos textos e entrevistas que se desejam estudar.

\section{Considerações finais}

Ao encaminhar o presente texto para a sua finalização, deve-se tornar claras algumas questões e realizar algumas sínteses, como as que se seguem:

a) Para a análise de discurso, torna-se necessária a compreensão de que o conjunto de discursos analisados é considerado como uma totalidade em si mesma, o que implica a necessidade de explicitar a sua lógica interna e a sua estrutura de organização, abrangendo, desta maneira, a produção de sentido realizada pelos sujeitos que será reconstruída a partir do modelo exposto acima. Neste caso, destaca-se que a abordagem da Teoria de 
Representações Sociais torna-se ainda mais importante como um elemento que, como um amálgama, fornece coerência interna ao dizer como fruto de construções simbólicas construídas socialmente e compartilhadas pelo grupo estudado;

b) As representações sociais desempenham um importante papel de comunicação entre a ideologia e as formações discursivas, fornecendo uma explicação para a dinâmica destas relações ao preencher, com a comunicação cotidiana, a interação social, a construção da identidade grupal e as construções simbólicas, dentre outras questões, um espaço que é de difícil compreensão, especialmente no mundo contemporâneo visto com mais fluidez e menor rigidez do que aquele do século anterior;

c) Por sua vez, os dispositivos analíticos são elementos promissores para a reconstrução empírica de conceitos teóricos de difícil demonstração na maioria dos estudos, com destaque para o núcleo figurativo e a objetivação, no caso da metáfora, e para a ancoragem, no do interdiscurso. A abordagem destes conceitos permite um aprofundamento da própria teoria e, ao mesmo tempo, um melhor delineamento dos objetos representacionais estudados;

d) Outro aspecto importante a ser destacado é com relação à permanência e às transformações representacionais demonstradas pelos processos discursivos através da relação entre a polissemia e a paráfrase: a primeira coisa que deve ser colocada é que esta afirmação deve ainda ser aprofundada teoricamente em futuros textos e comprovadamente empiricamente. A segunda é que, quando apontamos esta relação, especialmente no que tange à presença da polissemia, a mudança representacional seria indicada por um discurso estruturalmente formado por este dispositivo analítico, especialmente quando se pode comparar, em diferentes momentos, a discursividade do grupo estudado. Ou seja, um discursivo previamente organizado pela paráfrase, passa por situações de aparecimento de efeitos polissêmicos e depois se estrutura como polissêmico. No entanto, destaca-se que, no momento em que esta nova representação estiver estruturada e estabilizada, o que era polissemia se transformará em paráfrase, em completa harmonia e continuidade temporal com esta representação;

e) A linguagem não é opaca e possui certa espessura (como pontuado anteriormente), e, portanto, o discurso é permanentemente submetido à possibilidade do equívoco e da não compreensão. Diferente de métodos e técnicas de estudo mais quantitativas em que a análise dos resultados são mais objetivas, a interpretação (lembre-se que todo ato de interpretação é, por si mesmo, ideológico) de dados discursivos pode comportar perigos e armadilhas que fiquem mais "escondidos" (e em cuja exposição no trabalho acadêmico pode permanecer mais disfarçadas, inclusive). Por isto, propõe-se aqui que os resultados e as inferências sobre eles sejam sobre a estrutura do processo discursivo em sua totalidade e não somente sobre os elementos que o compõem, em íntima associação com a exterioridade do discurso, como a ideologia e as condições de produção do discurso.

Nos últimos parágrafos do presente texto, deve ser reconhecido que ainda permanecem diversos pontos da complexa relação entre a análise de discurso e a teoria de representações sociais que necessitam ser compreendidos e analisados, alguns, inclusive, que são consideradas barreiras epistemológicas que podem impedir um diálogo mais profícuo entre ambas, o que deverá ser alvo dos pesquisadores que se interessam neste encontro e na produção de conhecimento neste campo. Mas enquanto este conhecimento é 
produzido no cotidiano dos laboratórios e na rotina dos pesquisadores, pelo menos por ora, considera-se como promissora esta relação para ambos os campos teóricos.

\section{Referências}

Amaral, E. L. S., \& Rodrigues, M. L. (2012). A produção de sentido no campo teórico da AD: um processo de manifestação analítica a ser considerado. Revista Ave Palavra, 14(2), 1-12.

Arendt, H. (2010). A Condição Humana. Rio de Janeiro: Forense Universitária.

Bachelard, G. (2000). A poética do espaço. São Paulo: Martins Fontes.

Bakhtin, M. (1997). Problemas da Poética de Dostoiévski. Rio de Janeiro: Forense Universitária.

Bakhtin, M. (1992a). Marxismo e Filosofia da Linguagem. Problemas fundamentais do método sociológico na ciência da linguagem. São Paulo: Ed. Hucitec.

Bakhtin, M. (1992b). Estética da Criação Verbal. São Paulo: Martins Fontes.

Bonhome, M. (2008). Metáfora. In P. Charaudeau \& D. Maingueneau. (Orgs.). Dicionário de análise do discurso (pp. 328-332). São Paulo: Contexto.

Cassirer, E. (2012). Ensaio Sobre o Homem: introdução a uma filosofia da cultura humana. São Paulo: Editora WMF Martins Fontes.

Charaudeau, P. (2009). Identidade social e identidade discursiva, o fundamento da competência comunicacional. In M. Pietroluongo (Org.) O trabalho da tradução (pp. 309-326). Rio de Janeiro: Contra Capa.

Charaudeau, P. (2008). Condições de Produção do Discurso. In P. Charaudeau \& D. Maingueneau (Orgs.). Dicionário de análise do discurso (pp. 114-115). São Paulo: Contexto.

Courtine, J. J. (1981). Queleues problèmes théoriques et méthodologigues em analyse de discours. À propôs du dicours communiste adresse aux chrétiens. Langages, 62, 9-127.

DaMatta, R. (1986). O que faz o brasil, Brasil? Rio de Janeiro: Rocco.

Deconchy, J. P. (1989). Psychologie sociale, croyances et ideologies. Paris: Meridiens-Klincksieck.

Franco, M. L. P. (2004) Representações sociais, ideologia e desenvolvimento da consciência. Cadernos de Pesquisa, 34(121), 169-186.

Guareschi, P. (2000). Representações sociais e ideologia. Revista de Ciências Humanas, (Edição temática), 3346.

Henry, A. (1971). Métonymie et Métaphore. Paris: Klincksiek.

Jodelet D. (1998). Representações do contágio e a AIDS. In D. Jodelet. (Org.). AIDS e representações sociais: à busca de sentidos (pp. 17-45). Natal: EDUFRN.

Jodelet, D. (2001). Representações sociais: um domínio em expansão. In D. Jodelet (Org.). As representações sociais (pp. 17-44). Rio de Janeiro: EdUERJ.

Maingueneau, D. (2008). Interdiscurso. In P. Charaudeau \& D. Maingueneau. (Org.). Dicionário de análise do discurso (pp. 286-291). São Paulo: Contexto.

Marková, I. (2006). Dialogicidade e representações Sociais - as dinâmicas da mente. Petrópolis: Vozes.

Monteiro, M. B. (2013). Relações Intergrupais. In J. Vala \& M. B. Monteiro (Org.). Psicologia Social. Lisboa: Faculdade Calouste Gulbenkian.

Moscovici, S. (1961). La psychanalise: son image et son public. Paris: PUF.

Moscovici, S. (2003). Representações Sociais: investigações em psicologia social. Petrópolis: Vozes.

Moscovici, S. (2012). A psicanálise, sua imagem e seu público. Petrópolis: Vozes. 
Orlandi, E. (2001a). Análise de discurso: princípios e procedimentos. Campinas: Pontes.

Orlandi, E. (2001b). Discurso \& Leitura. São Paulo/Campinas: Cortez/Ed. Unicamp.

Orlandi, E. (1986). A análise do discurso: algumas observações. Revista de documentação de estudos em lingüística teórica e aplicada, 2,105-126.

Orlandi, E. (2002). Interpretação: autoria, leitura e efeitos do trabalho simbólico. Petrópolis: Ed. Vozes.

Orlandi, E. (2003). A linguagem e seu funcionamento: as formas do discurso. Campinas: Pontes.

Pêcheux, M. (1996). Semântica e discurso: uma crítica à afirmação do óbvio. Campinas: Ed. Unicamp.

Pêcheux, M. (2001). Análise Automática do Discurso. In F. Gadet \& T. Hak. (Orgs.). Por uma Análise Automática do Discurso: uma introdução à obra de Michel Pêcheux (pp. 61-161). Campinas: Editora da Unicamp.

Pêcheux, M., \& Fuchs, C. (2001). A propósito da análise automática do discurso: atualização e perspectivas. In F. Gadet \& T. Hak (Orgs.). Por uma análise automática do discurso: uma introdução à obra de Michel Pêcheux (pp. 163-252). Campinas: Editora da Unicamp.

Rateau, P., Ernest-Vintila, A., \& Delouvée, S. (2012). Michel-Louis Rouquette et le Modèle de l'architecture de la pensée sociale. Psicologia e Saber Social, 1(1), 53-65.

Rouquette, M.-L. (1996). Représentations sociales et idéologie. In J.-C. Deschamps \& J.-L. Beauvois (Orgs.). Des attitudes aux attributions. Sur la construction de la réalité sociale (pp. 163-173). Grenoble: PUG.

Rouquette, M.-L. (2009). La pensée sociale. Perspectives fondamentales et recherches appliquées. Toulouse: Erès.

Santos, M. F. S. (1994). Representação social e a relação indivíduo-sociedade. Temas em psicologia, 2(3), 133142.

Tajfel, H. (1972). La catégorisation sociale. In S. Moscovici (Org.). Introduction à la psychologie sociale (pp. 272 300). Paris: PUF.

Xavier, R. (2002). Representação social e ideologia: conceitos intercambiáveis? Psicologia \& Sociedade, 14(2), 18-47. 